\title{
Cloning and sequencing of the Candida albicans homologue of SRB1/PSA1/VIG9, the essential gene encoding GDP-mannose pyrophosphorylase in Saccharomyces cerevisiae
}

\author{
Saradee Warit, Richard. M. Walmsley and Lubomira I. Stateva \\ Author for correspondence: Lubomira I. Stateva. Tel: +44161200 4208. Fax: +441612360409. \\ e-mail: lubomira.stateva@umist.ac.uk
}

Department of Biomolecular Sciences, UMIST, PO Box 88, Manchester M60 1QD, UK

\begin{abstract}
Two genomic fragments have been isolated from Candida albicans which strongly hybridize to SRB1IPSA1/VIG9, an essential gene which encodes GDPmannose pyrophosphorylase in Saccharomyces cerevisiae. A common 2.5 kb Xbal-Pstl fragment has been identified, which Southern analysis suggests is most likely unique in the $C$. albicans genome. The fragment contains an ORF, which is $82 \%$ identical and $90 \%$ homologous to the Srb1p/Psa1p/Vig9p from S. cerevisiae, contains one additional amino acid at position 254 and is able to functionally complement the major phenotypic characteristics of $S$. cerevisiae srb1 null and conditional mutations. The authors therefore conclude that they have cloned and sequenced from $C$. albicans the bona fide homologue of SRB1IPSA1/VIG9, named hereafter CaSRB1. Northern analysis data indicate that the gene is expressed in C. albicans under conditions of growth in the yeast and hyphal form and suggest that its expression might be regulated.
\end{abstract}

Keywords: SRB1/PSA1/VIG9, glycosylation, GDP-mannose, Candida albicans, cell wall

\section{INTRODUCTION}

Yeast cells, unlike mammalian cells, are surrounded by a thick cell wall, which is a particularly attractive target for antifungal drugs (Debono \& Gordee, 1994). The yeast cell wall consists of three major components glucans, mannans and chitin-and the structural features and interactions of these components are relatively well understood (Klis, 1994). In recent years two MAP kinase signalling pathways (PKC1 and HOG1) and the Ras/cAMP dependent pathway have been shown to regulate cell wall integrity in Saccharomyces cerevisiae (Cid et al., 1995; G. Tomlin, S. G. Oliver \& L. I. Stateva, unpublished results).

The cell wall performs a number of functions, the most important of which are cell shape determination, regulation of permeability, protection against damaging

Abbreviations: MAP kinase, mitogen-activated protein kinase; YAC, yeast artificial chromosome.

The GenBank/DDBJ/EMBL accession numbers for the sequences reported in this paper are AF030299 and AF030300. extracellular agents and, in pathogenic species like Candida albicans, expression of virulence properties. The cell wall is a highly dynamic organelle which can undergo modifications to its composition and structural features in response to both developmental and environmental signals. Significant variations have been reported for mannoproteins in particular. In $S$. cerevisiae, differences in mannoprotein synthesis during development of the bud and that of mature cells result in differences in permeability (de Nobel et al., 1991). Mannoprotein composition and structure are also very different at the schmoo projection, which develops in response to pheromones (Lipke et al., 1976; Herrero et al., 1985). In C. albicans, cell wall mannoproteins specific only for the hyphal form have been described (Elorza et al., 1985; Casanova et al., 1989). For these reasons the mannoproteins, their synthesis and regulation, are a good target for the development of selective antifungal drugs. Mannans are synthesized by an elaborate mechanism of post-translational modifications carried out during passage through the secretory pathway (Lehle \& Tanner, 1995; Herscovics \& Orlean, 1993) and all of these (N-, O-linked glycosylation and 
GPI-anchor synthesis) require a common substrateGDP-mannose. Its synthesis is, therefore, of key importance in the biogenesis of a functional cell envelope in yeast.

The gene which encodes the GDP-mannose pyrophosphorylase in S. cerevisiae is an essential, cell-cycleregulated gene. It has been independently isolated as a multicopy suppressor of both alg1-PSA1 (Albright \& Robbins, 1990; Benton et al., 1996) and dpm1 (Orlean et al., 1988; J. Schultz \& G. Sprague, unpublished data in the SGD database), as the bona fide SRB1 (G. Tomlin, S. G. Oliver \& L. I. Stateva, unpublished results) and VIG9 (Hashimoto et al., 1997). The existing mutant alleles of the SRB1 gene produce highly pleiotropic cell wall integrity defects: dependence for growth upon the presence of osmotic stabilizers in the medium, lysis upon osmotic shock (Venkov et al., 1974) and high competence for DNA transformation, including that with large YACs (Heale et al., 1994). Repression of SRB1/ PSA1 expression reveals additional phenotypes suggesting that the gene is also required for bud-site selection and cytokinesis (Zhang, 1997). A number of structural and compositional differences in the major cell wall components glucan and mannan have also been reported (Maerkisch et al., 1983; Blagoeva et al., 1991). Mutations in SRB1 (srb1-1) are synthetically lethal with $p k c 1$, but cannot be rescued by overexpression of either $P K C 1$, or any of the downstream components of the PKC1-regulated MAP kinase signal transduction pathway (Cid et al., 1995). However, overexpression of PDE2 (the gene encoding the high-affinity cAMP phosphodiesterase: Sass et al., 1986) restores the wildtype phenotype of srb1-1 mutants (G. Tomlin, S. G. Oliver \& L. I. Stateva, unpublished results).

In the present paper the cloning and molecular characterization of the SRB1/PSA1 homologue from C. albicans is reported. Southern analysis shows that it is unique in the $C$. albicans genome. Sequence determination indicates that it encodes a highly conserved protein, which is $82 \%$ identical and $90 \%$ homologous to its $S$. cerevisiae counterpart. The potential role of this gene in the dimorphic switch of $C$. albicans is discussed on the basis of the results of the Northern analysis of its expression under conditions of hyphal induction by serum or changes in $\mathrm{pH}$.

\section{METHODS}

Strains and media. Strains of Saccharomyces cerevisiae, Candida albicans and Escherichia coli used in this study are listed in Table 1. Media to support the growth of $S$. cerevisiae and C. albicans (rich YEPD and minimal SD, containing YNB, glucose and appropriate supplements) were prepared according to Sherman et al. (1986). All types of media for the propagation of srb1-1 fragile mutants were supplemented with $10 \%(\mathrm{w} / \mathrm{v})$ sorbitol. Minimal medium for $\mathrm{pH}$ hyphal induction in C. albicans was prepared essentially as described by Lee et al. (1975). Bacterial strains were grown in LB and LB with ampicillin, as described by Sambrook et al. (1989).

Yeast library and plasmids. The C. albicans genomic library was kindly provided by $\operatorname{Dr}$ S. Scherer, University of
Minnesota, USA. It was constructed using the fosmid pFOS1 (Kim et al., 1992) and fragments of Sau3AI partially digested genomic DNA from C. albicans 1161. The 1920 clones obtained were transferred to Hybond- $\mathrm{N}^{+}$membranes (Amersham Pharmacia Biotech). These membranes were used for hybridization with a labelled $S$. cerevisiae SRB1/PSA1 $0.8 \mathrm{~kb}$ EcoRI-BglII DNA fragment, isolated from plasmid SRB1-9b (kindly provided by G. Tomlin). All plasmids used in this study are listed in Table 1.

DNA preparation and manipulations. Yeast genomic DNA was isolated from spheroplasts (Davis et al., 1980). Bacterial plasmid DNA, on both a small $(1 \mathrm{ml})$ and a large $(50-100 \mathrm{ml})$ scale, was isolated using the alkaline-lysis method of Birnboim \& Doly (1979), as described by Sambrook et al. (1989). DNA was purified either by CsCl gradient centrifugation (Sambrook et al., 1989) or by a Qiagen QUA filter plasmid Midi kit. All DNA fragments used for subcloning were gel-purified by the method of Heery et al. (1990). Enzymic reactions with restriction enzymes (Boehringer), $\mathrm{T}_{4}$ ligase (Boehringer) and Taq DNA polymerase (Amersham Pharmacia Biotech) were all performed according to the recommendations of the manufacturers. For Southern analysis, the procedure recommended by Amersham Pharmacia Biotech was followed. All DNA probes used for hybridization were labelled with the Rediprime kit and Redivue $\left[\alpha^{-32} \mathrm{P}\right] \mathrm{dCTP}\left(10 \mathrm{mCi} \mathrm{ml}^{-1}, 1 \mathrm{Ci}=\right.$ $3.7 \times 10^{10} \mathrm{~Bq}$ ) from Amersham Pharmacia Biotech.

Hyphal induction, RNA extraction and Northern blotting. Hyphal induction by serum and $\mathrm{pH}$ was achieved essentially by the methods of Bailey et al. (1996) and Sundstrom et al. (1990), respectively. The control alternative experiments, where the strains were growing only in the yeast form, were performed in both rich (YEPD) and minimal (Lee's medium, $\mathrm{pH} 4.5$ ) medium at $25^{\circ} \mathrm{C}$ after an initial $2 \mathrm{~h}$ starvation in water for synchronization of growth. The cell cycle phase of the cultures was determined by counting the budded and unbudded cells in the course of the experiments. Samples were withdrawn at various times $(0 \cdot 5,1,2,3,4$ and $6 \mathrm{~h})$ after hyphal induction (either method) and during the control experiments, and used for RNA extraction. Total RNA, isolated as described by Brown (1994), was denatured in formaldehyde/ formamide, and after electrophoresis under denaturing conditions, transferred to Hybond-N membranes (Amersham Pharmacia Biotech). The membranes were treated and hybridized to labelled DNA probes, as recommended by the manufacturers. After hybridization, they were exposed to a Bio-Rad imaging screen, developed with the Bio-Rad phosphorimager (GS-363) and analysed with Molecular Analyser software. As an alternative probe for loading and transfer of the total RNA, the gene TEF3 (Swoboda et al., 1994) was used. However, CaSRB1 mRNA levels were quantified relative to the rRNAs, loading approximately equal amounts and measuring the ethidium bromide staining intensity in each lane. The levels of expression at given time points were determined relative to that at $30 \mathrm{~min}$ after the start of the growth under all conditions.

DNA sequence analysis. The method employed for sequencing was essentially as described by James et al. (1995). Nucleotide sequence analyses and homology searches were performed using both the BLAST search program (http : / / www.ncbi.nlm.nih.gov / cgi - bin / BLAST / nph - blast) and the Clustal w (1.60) Multiple Sequence Alignment program (http://www.genome.ad.jp/SIT/SIT.html).

Genetic methods. The concomitant loss of plasmid markers and the mitotic stability of transformed strains were tested by growing the cultures to the stationary phase in rich (YEPD) 
Table 1. Strains and plasmids used in this study

\begin{tabular}{|c|c|c|}
\hline Strain & Relevant genotype or details & Source/reference \\
\hline \multicolumn{3}{|l|}{ S. cerevisiae } \\
\hline 7SLU & MAT $\alpha$ srb1-1 leu 2 ura 3 & Stateva et al. (1991) \\
\hline $\mathrm{AH} 22$ & $\begin{array}{l}\text { MATa leu2-3, leu2-112 bis4-519 } \\
\text { can1 }\end{array}$ & UMIST collection \\
\hline 20hPS1-2d MET3-PSA1 & $\begin{array}{l}\text { MAT a leu2 ura3 trp1 ade1 his2 } \\
\text { psa1::TRP1 pURA3/MET3-PSA1 }\end{array}$ & Zhang (1997) \\
\hline \multicolumn{3}{|l|}{ C. albicans } \\
\hline SC5314 & Wild-type & Gillum et al. (1984) \\
\hline CAI4 & $\Delta u r a 3:: i m m 434 / \Delta u r a 3:: i m m 434$ & Fonzi \& Irwin (1993) \\
\hline \multicolumn{3}{|l|}{ E. coli } \\
\hline XL-1 Blue & $\begin{array}{l}\text { recA1 end A1 gyrA96 thi-1 bsdR17 } \\
\text { supE44 relA1 lac } \\
{\left[\mathrm{F}^{\prime} \text { proABlacl }{ }^{\mathrm{q}} \mathrm{Z} \Delta \mathrm{M} 15 \text { Tn10 }\left(\mathrm{Tet}^{\mathrm{R}}\right)\right]}\end{array}$ & Bullock et al. (1987) \\
\hline \multicolumn{3}{|l|}{ Plasmids } \\
\hline pUC19 & E. coli vector & Yanisch-Perron et al. (1985) \\
\hline pRS415 & $C E N-A R S-L E U 2$ & Sikorski \& Hieter (1989) \\
\hline SRB1-4 & $\begin{array}{l}\text { YCp50 based, SRB1-2 with the ClaI } \\
\text { fragment removed }\end{array}$ & $\begin{array}{l}\text { G. Tomlin, Dept of } \\
\text { Biomolecular Sciences, } \\
\text { UMIST }\end{array}$ \\
\hline SRB1-9b & $\begin{array}{l}\text { ClaI-BamHI fragment of } S R B 1 \\
\text { in pRS316 }\end{array}$ & $\begin{array}{l}\text { G.Tomlin, Dept of } \\
\text { Biomolecular Sciences, } \\
\text { UMIST }\end{array}$ \\
\hline pA301 & $\begin{array}{l}\text { EcoRI-BamHI fragment of } \\
\text { S. cerevisiae ACT1 }\end{array}$ & $\begin{array}{l}\text { J. Rosamond, University of } \\
\text { Manchester, UK }\end{array}$ \\
\hline
\end{tabular}

medium containing $10 \%$ sorbitol at $30^{\circ} \mathrm{C}$ and plating out aliquots for single colonies on plates of the same medium. After incubation at $30^{\circ} \mathrm{C}$ the colonies were replica-plated to selective media. Sorbitol dependence of the $S$. cerevisiae strain 7SLU (Table 1) and transformants, containing C. albicans SRB1/PSA1 putative homologues, was tested by comparing the growth of single colonies on minimal media with and without $10 \%$ sorbitol, in the presence of the appropriate nutritional supplements.

Cultures of strains containing the pMET3-regulated SRB1/ PSA1 cassette were grown in selective SD medium at $30^{\circ} \mathrm{C}$ with vigorous shaking until the early exponential phase $\left(\mathrm{OD}_{600}\right.$ 0.05 ), at which point they were split into two halves. To one half of each culture, methionine was added to a final concentration of $2 \mathrm{mM}$; to the other half, an equivalent volume of distilled water was added. The two cultures were then incubated further under the same conditions as before, until stationary phase.

Lysis test. The standard procedure, described by Stateva $e t$ al. (1991), was followed. All tests were performed after growth of the strains in selective minimal media to ensure maximum stability of the transforming plasmids.

Transformation. E. coli XL-1 Blue was transformed either by the calcium chloride method or by the DMSO method, as described by Sambrook et al. (1989). Yeast strains were transformed either by a modification of the lithium procedure of Ito et al. (1983), as described by Stateva et al. (1991) or by the DMSO enhanced procedure developed by Hill et al. (1991).

PCR. The SRB1 forward (5'-AGCTCAGAGGTCACTATACG-3') and reverse (5'-CGGGATCCAATACTACAGACAT-
TGATAGCC-3') primers were used to amplify the $S$. cerevisiae SRB1/PSA1. In $50 \mu \mathrm{l}$ of PCR reaction, $5 \mathrm{ng}$ DNA template (SRB1-4) was mixed with $200 \mathrm{ng}$ of each primer, $1.5 \mathrm{mM} \mathrm{MgCl}, 200 \mu \mathrm{M}$ dNTPs, 0.5 unit Taq polymerase (Boeringer) and PCR buffer. The PCR amplification was run for 30 cycles $\left(94^{\circ} \mathrm{C}\right.$ for $1 \mathrm{~min}, 55^{\circ} \mathrm{C}$ for $1 \mathrm{~min}$ and $72{ }^{\circ} \mathrm{C}$ for $2 \min 15 s)$.

\section{RESULTS}

\section{The SRB1/PSA1/VIG9 putative homologue from C. albicans is unique}

In $S$. cerevisiae the gene SRB1/PSA1 is essential for growth. Speculating that $S R B 1 / P S A 1$ might be a highly conserved gene among yeast species, it was decided to attempt the isolation of a C. albicans homologue by DNA sequence hybridization with an ordered fosmid library, using the internal $0.8 \mathrm{~kb} E c o \mathrm{RI}-B g l \mathrm{II}$ fragment from the $S$. cerevisiae SRB1/PSA1 gene as a probe. After two consecutive rounds of screening, two strongly hybridizing clones (designated A and B) were selected for further analysis. They were shown to have inserts of around $45 \mathrm{~kb}$ (data not shown) with a common $6 \mathrm{~kb}$ $\mathrm{X} b a \mathrm{I}$ fragment. At this initial stage of characterization two polymorphisms were observed in the restriction patterns of the two recombinant clones. Clone A contained an EcoRI site, absent from clone B, whilst clone B had a PstI site, not found in clone A. Subcloning

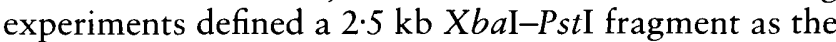
smallest uniquely hybridizing region of the C. albicans 
(a)

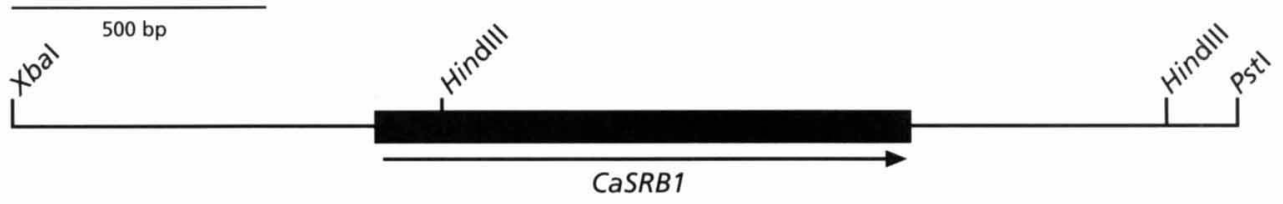

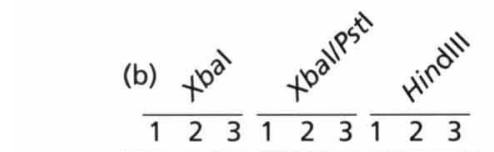

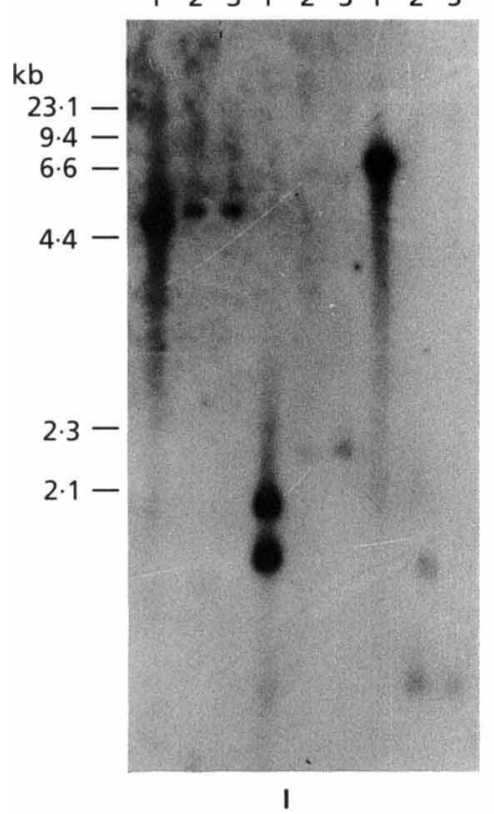

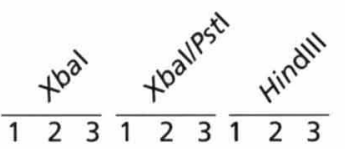

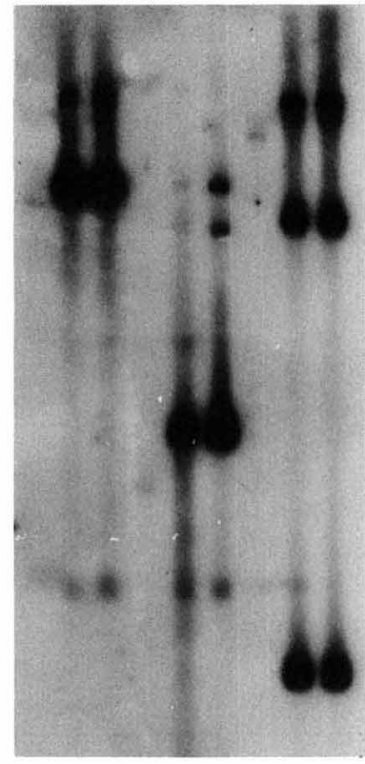

II

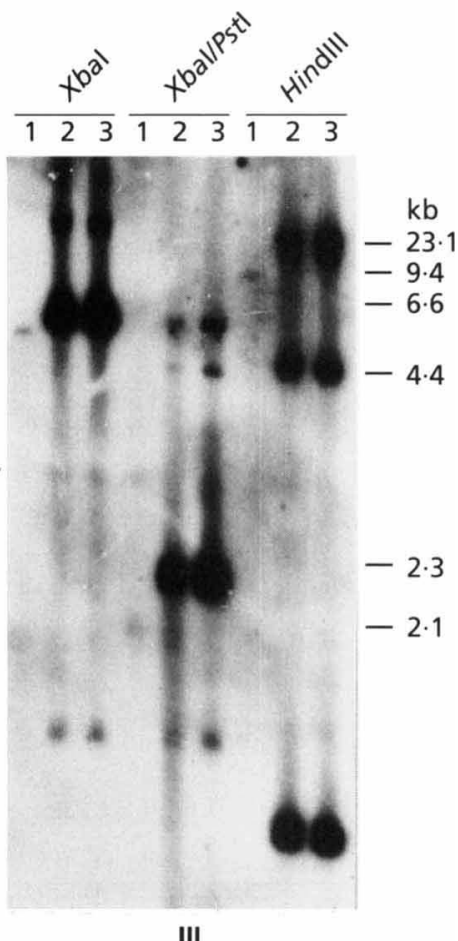

III

Fig. 1. Southern analysis. (a) Restriction map of the $C$. albicans probes. (b) Total genomic DNAs of S. cerevisiae AH22 (lane 1) and C. albicans SC5314 and CAI4 (lanes 2 and 3, respectively) were digested with Xbal, Xbal/Pstl and HindIII and hybridized with S. cerevisiae SRB1 probe (I), and with the $2.5 \mathrm{~kb}$ Xbal-Pstl fragments from clones A and B (II and III, respectively).

DNA inserts and this was used in subsequent experiments.

Southern analysis was used to check whether the putative SRB1/PSA1 homologue from clones A and B defined unique sequences in the Candida genome. Total genomic DNA was isolated from two C. albicans strains, CAI4 and SC5314, and digested with two enzymes without cleavage sites in the SRB1/PSA1 gene of $S$. cerevisiae (XbaI and HindIII) and one enzyme with an internal cleavage site $(P s t \mathrm{I})$. Genomic DNA from $S$. cerevisiae AH22 was similarly treated. The $2.5 \mathrm{~kb}$ XbaI-Pst I fragments from C. albicans clones A and B, and a PCR-amplified fragment of the $S$. cerevisiae SRB1 gene, were used as probes. The results of the Southern analysis with the three different hybridization probes, together with the restriction map of the XbaI-PstI fragment from C. albicans generated on the basis of the preliminary cloning experiments, are presented in Fig. 1. In all three cases, the signals from the homologous probing experiments were stronger [with $S$. cerevisiae DNA in Fig. 1(bI), and with C. albicans DNAs in Fig. 1 (bII and bIII)], than those from the heterologous probing. The hybridization pattern of the $S$. cerevisiae DNA, seen best in Fig. 1(bI), confirmed the presence of all the expected fragments. The patterns of the two strains of C. albicans, which were identical to each other, were significantly different from that of the $S$. cerevisiae strain: note the different PstI/XbaI and HindIII patterns. However, they verified the restriction map (Fig. 1a) of the cloned C. albicans fragment, which has unique sites for $X b a I$ and PstI, and two sites for HindIII. There are one or two very faint additional bands which must contain regions of limited similarity; however, given the intensity of the main bands, it was concluded that, like the SRB1/PSA1 gene in $S$. cerevisiae, its putative homologue from C. albicans is most likely also unique.

\section{Functional complementation of srb1-1-associated phenotypes with the C. albicans SRB1/PSA1 homologue}

Mutations of SRB1 are highly pleiotropic in their phenotypic effects, with the most characteristic features of srb1-1 being dependence on osmotic stabilizers for 

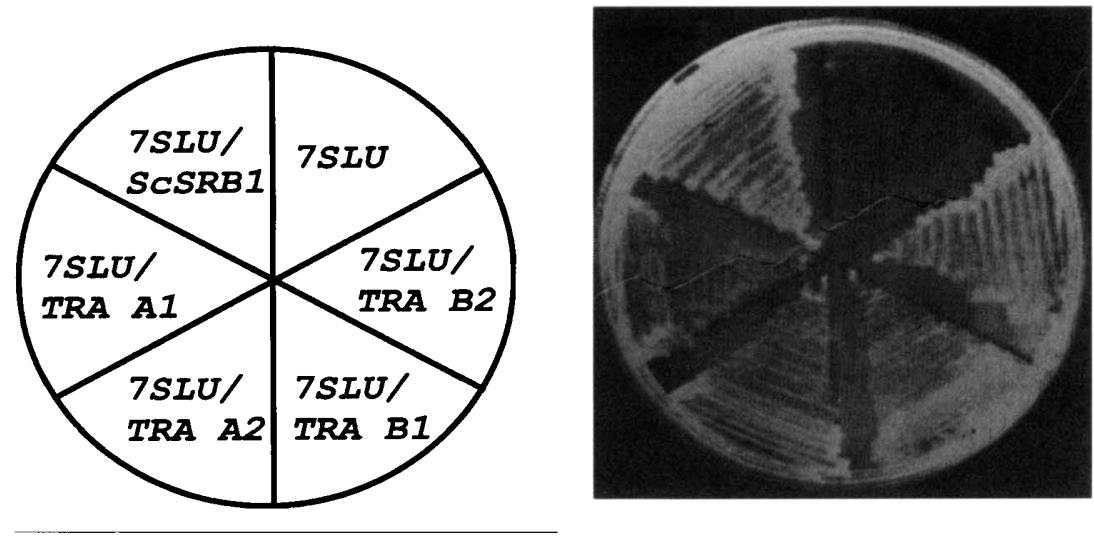

Fig. 2. Functional analysis test. The srb1-1 mutant 7SLU was transformed with centromeric plasmids (for description of constructs see Methods) containing CaSRB1 either from clone $A$ (TRA $A 1$ and TRA A2) or clone B (TRA B1 and TRA B2). For comparison the mutant $7 \mathrm{SLU}$, as well as a transformant carrying the $S$. cerevisiae SRB1/PSA1 gene (7SLU SCSRB1), are also included on the same plate, which contained minimal medium without sorbitol. growth and lysis upon osmotic shock. These phenotypes were chosen for the functional complementation test. The $S$. cerevisiae srb1-1 mutant strain (7SLU) was transformed with pRS415 only (Sikorski \& Hieter, 1989), and with recombinant plasmids carrying either the clone A or the clone B $2.5 \mathrm{~kb} X b a \mathrm{I}-$ PstI fragment. One hundred transformants for each recombinant plasmid were tested and, unlike the srb1-1 mutant 7SLU, and the strain containing only pRS415, they were all able to grow without the addition of $10 \%$ sorbitol to the medium (examples are shown in Fig. 2). A mitotic stability test was performed on three transformants of each type. It confirmed that their newly acquired feature co-segregated in all cases with the plasmid-borne nutritional marker LEU2.

The ability of the putative C. albicans SRB1 homologues to complement the lysis phenotype of the srb1-1 mutant was also tested. The standard lysis test, as described in Methods, was performed with two different transformants of each type and the original mutant. All strains were grown in minimal selective media for maximum stability of the transforming plasmids. The results indicated clearly that the putative $C$. albicans SRB1 homologues relieve the osmotic shock sensitivity of $S$. cerevisiae srb1-1 mutants (data not shown).

To rule out the possibility of allele-specific complementation, the same recombinant plasmids were also transformed into the srb1 null mutant, 20hPS1-2d, modified by Zhang (1997); see Table 1 for genotype. The strain contains a wild-type copy of the SRB1/PSA1 gene under the control of the tightly regulated MET3 promoter (Mountain et al., 1991). As a result, the strain grows as wild-type in the absence of methionine, but the cells quickly stop growing and lose viability upon addition of $2 \mathrm{mM}$ methionine to the medium (Zhang, 1997). Transformants of this strain carrying the putative $C$. albicans SRB1/PSA1 homologues were able to grow normally in methionine-supplemented medium and reached cell densities comparable to those of the control cultures without methionine (Table 2).

On the basis of these results, it was concluded that the two C. albicans clones A and B contain a common $2 \cdot 5 \mathrm{~kb}$

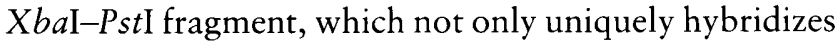
to the $S$. cerevisiae $S R B 1$ gene and to $C$. albicans genomic DNA, but is also able to functionally comp-
Table 2. Complementation of the lethality of srb1 null mutants by $C$. albicans SRB1 homologues

The results are means of three independent experiments \pm SD.

\begin{tabular}{|c|c|c|}
\hline \multirow[t]{2}{*}{ Strain } & \multicolumn{2}{|c|}{$\mathrm{OD}_{600}$} \\
\hline & Minus methionine & Plus methionine \\
\hline Control* & $1 \cdot 2 \pm 0.05$ & $0 \cdot 3 \pm 0 \cdot 03$ \\
\hline TRA A1t & $1 \cdot 2 \pm 0.03$ & $1 \cdot 2 \pm 0.06$ \\
\hline TRA A2† & $1 \cdot 18 \pm 0 \cdot 07$ & $1 \cdot 28 \pm 0 \cdot 01$ \\
\hline TRA A3† & $1 \cdot 22 \pm 0 \cdot 03$ & $1 \cdot 11 \pm 0 \cdot 05$ \\
\hline TRA B1‡ & $1.02 \pm 0.04$ & $1 \cdot 22 \pm 0.05$ \\
\hline TRA B2 $\ddagger$ & $1 \cdot 18 \pm 0 \cdot 01$ & $1.01 \pm 0.08$ \\
\hline TRA B3‡ & $1 \cdot 22 \pm 0 \cdot 02$ & $1 \cdot 05 \pm 0.04$ \\
\hline
\end{tabular}

*Strain 20hPS1-2d MET3-PSA1 (see Table 1 for relevant genotype) was used as a control.

TTRA A1, 2 and 3 are three independent transformants of 20hPS1-2d MET3-PSA1 obtained with the C. albicans SRB1/ PSA1 homologue isolated from clone A.

$\neq$ TRA B1, 2 and 3 are three independent transformants of 20hPS1-2d MET3-PSA1 obtained with the C. albicans SRB1/ PSA1 homologue isolated from clone B.

lement the major phenotypic characteristics of two different srb1 mutant alleles.

Whilst working with the $S$. cerevisiae 7SLU srb1-1 transformants, carrying the putative SRB1 C. albicans homologues, an additional phenotype was observed. The transformants carrying the recombinant plasmids, but not the cloning vector, lost viability very rapidly in stationary phase, irrespective of the type of medium (rich or minimal), or the temperature $\left(4,22\right.$ or $30^{\circ} \mathrm{C}$ ). In all cases tested, the percentage of viable cells decreased very rapidly and was almost zero after only $3 \mathrm{~d}$ (data not shown).

\section{DNA sequence and predicted ORF of the SRB 1/PSA1 homologue from C. albicans (CaSRB1)}

The sequence of the SRB1/PSA1 homologues represented by both clones $\mathrm{A}$ and $\mathrm{B}$ was determined, as described in Methods. A single ORF, encoding a putative 


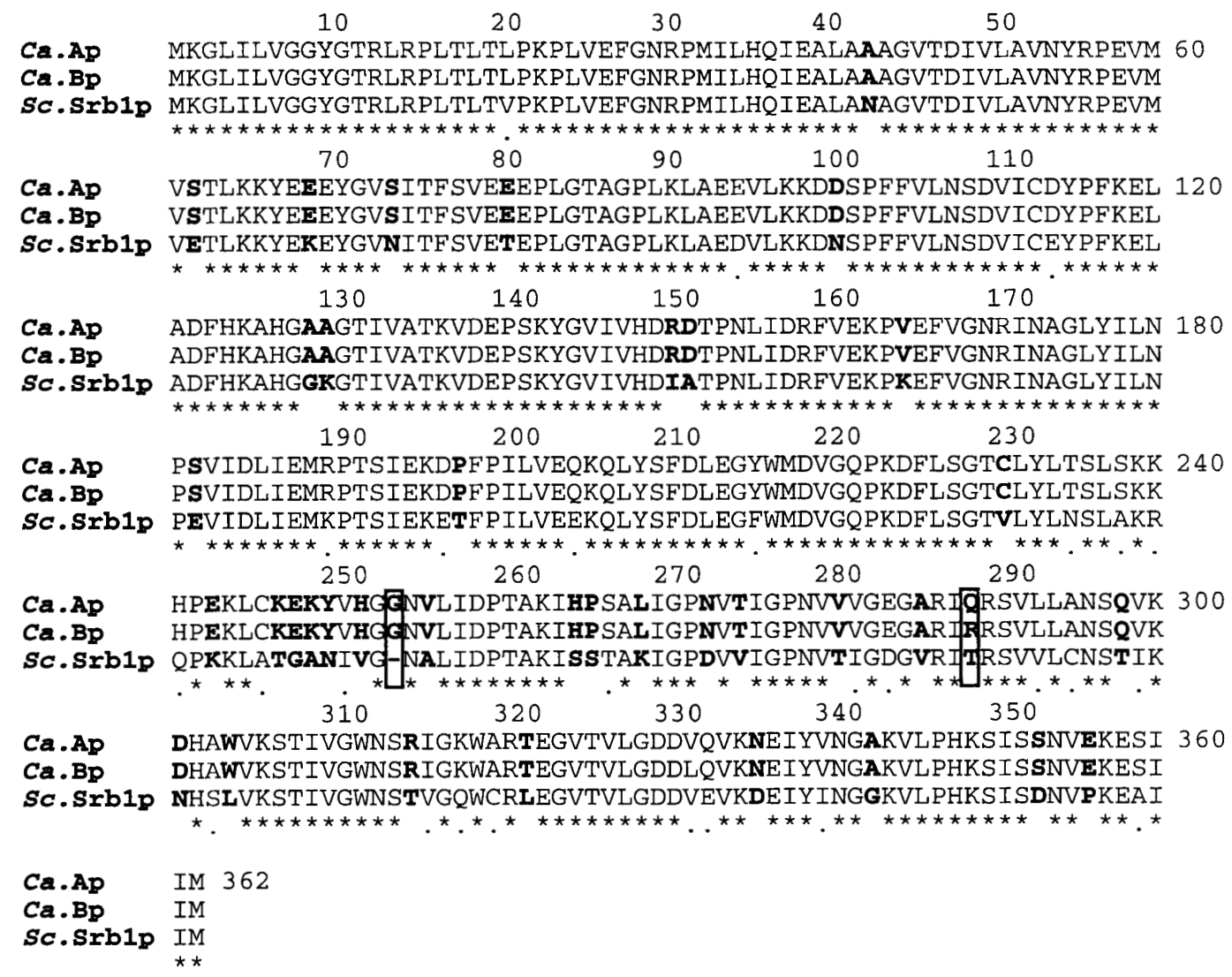

Fig. 3. Comparison of the deduced amino acid sequences of the two putative $C$. albicans SRB1/PSA1 (Ca.Ap and Ca.Bp) and S. cerevisiae SRB1/PSA1 (Sc.Srb1p). Amino acids given in bold correspond to differences, asterisks to identities and dots to similarities in the deduced C. albicans and S. cerevisiae protein sequences. The amino acids in boxes (positions 254 and 288 ) correspond to an insertion in the Candida protein in comparison to the $S$. cerevisiae counterpart, and to the only difference between the two $C$. albicans protein sequences, respectively.

product of 362 amino acids, was identified. The first ATG of this ORF is 77 bp downstream from a TATAA box. The $3^{\prime}$ region of the gene contains two in-frame stop codons 21 nucleotides downstream of the final codon and a consensus site for transcription termination (TATG) 137 nucleotides downstream of the final codon. No polyadenylation consensus sequences could be identified within the sequenced regions.

The predicted protein sequence of this new gene (called CaSRB1) has an estimated molecular mass of about $40 \mathrm{kDa}$ (39961 Da for clone A; $39989 \mathrm{Da}$ for clone B). A comparison between the protein sequences of the two Candida clones, together with that of $S$. cerevisiae Srb1p, is given in Fig. 3. The following points are noteworthy. First, there is only one significant difference between the two C. albicans clones: at position 288, the encoded amino acid is Gln in clone A and Arg in clone $B$. Second, there is a very high percentage of identity $(82 \%)$ and homology $(90 \%)$ between the C. albicans and $S$. cerevisiae sequences. Third, the amino acid at position 254 in the C. albicans sequence is not present in the corresponding position of the $S$. cerevisiae protein.

Fig. 4 shows the hydropathy profile of the predicted CaSRB1 protein. The profile suggests that, like the $S$.

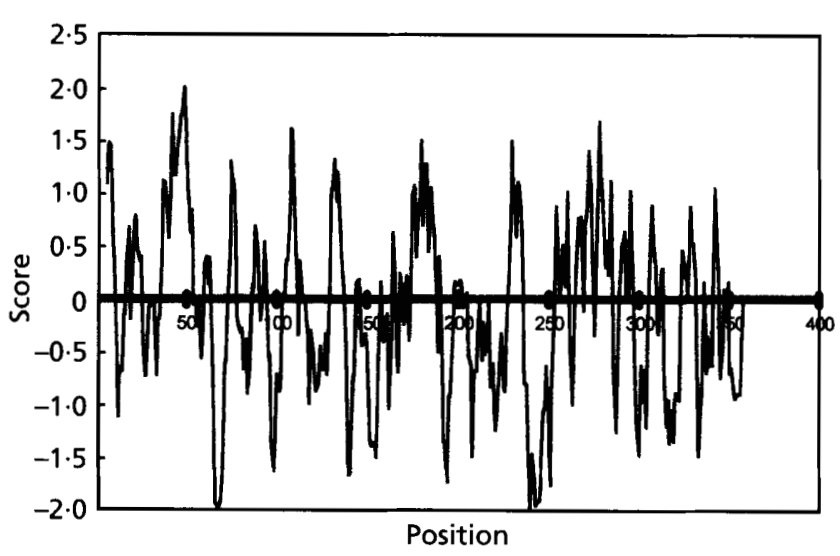

Fig. 4. Hydropathy profile of the predicted C. albicans homologue of SRB1/PSA1 from clone A. The Position scale runs from 0 to 400 .

cerevisiae counterpart (Hashimoto et al., 1997), the protein from C. albicans is soluble and does not have hydrophobic stretches long enough to be considered potential transmembrane domains or signal sequences for secretion. 

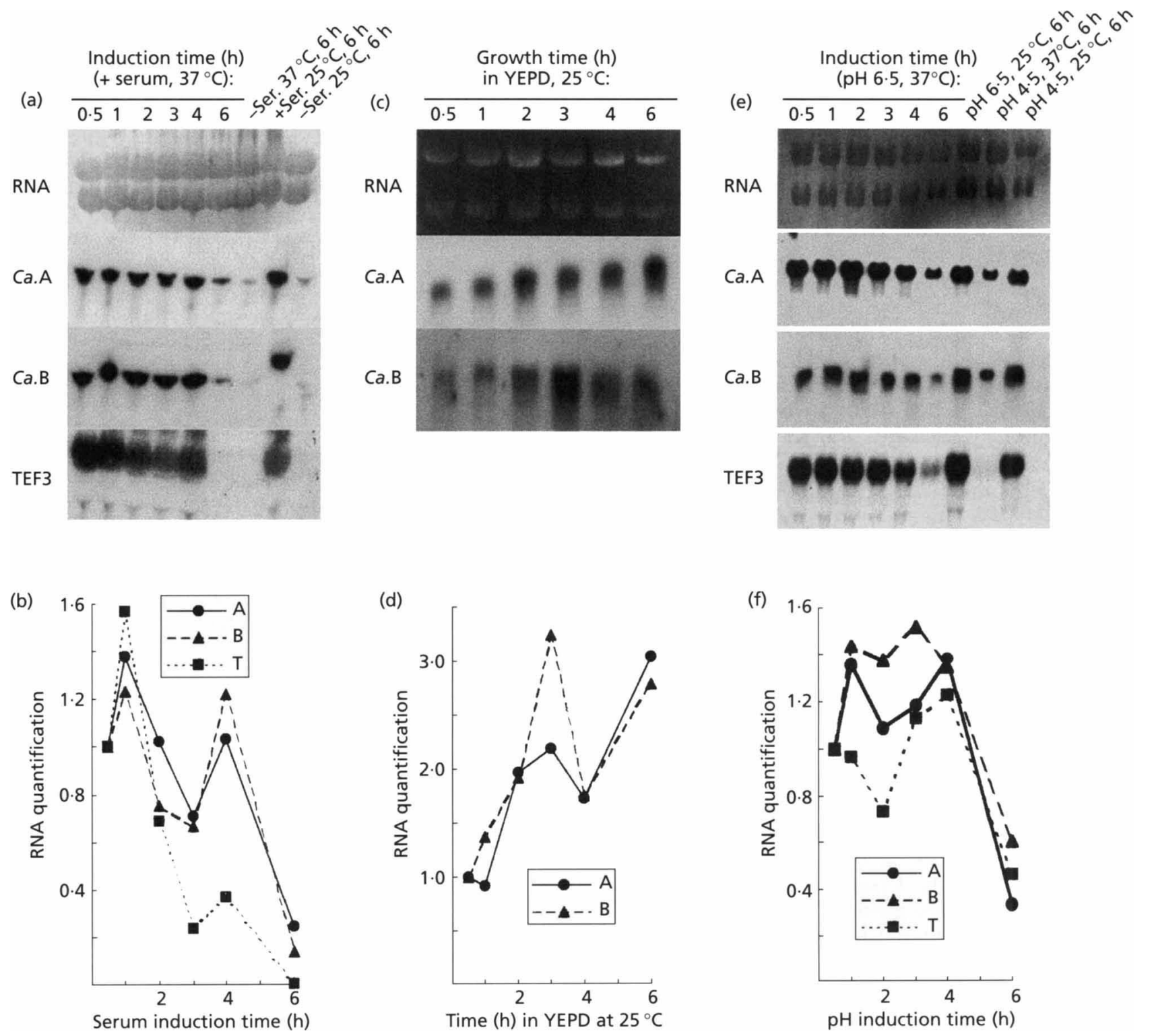

Fig. 5. Northern analysis of total mRNA from C. albicans SC5314 after induction of hyphae by serum (a) and pH (e), and during growth in the yeast form in rich medium (c). Panels (a), (c) and (e) show, from top to bottom: ethidium bromide staining pattern, hybridization results with probe $A$, hybridization results with probe $B$ and (a and e only) hybridization with TEF3 as a probe (T). Times of induction and growth and conditions of controls are shown above the tracks. Panels (b), (d) and (f) show levels of expression after quantification of the Northern results, as described in Methods. Levels at all time points are expressed relative to that taken $30 \mathrm{~min}$ after start of experiments.

\section{Northern analysis}

The expression of CaSRB1 was investigated during yeast-to-hyphal transition and also under conditions of yeast-only growth. The dimorphic switch was induced by either addition of serum or $\mathrm{pH}$ change, and both combined with a higher growth temperature $\left(37^{\circ} \mathrm{C}\right)$. At a pH of 4.5 and a temperature of $25^{\circ} \mathrm{C}$ in minimal medium, and also in rich medium at the same temperature, C. albicans grows purely as a yeast. When the $\mathrm{pH}$ and the temperature are increased to 6.5 and $37^{\circ} \mathrm{C}$ respectively, or when $10 \%$ serum is added to the rich medium at $37^{\circ} \mathrm{C}$, the cells undergo a morphogenic switch, forming first germ tubes, then hyphae. Under the conditions of our experiments, the first germ tubes were clearly visible $30 \mathrm{~min}$ after induction (either method) and the hyphal transition was completed after $4 \mathrm{~h}$ (data not shown). The pattern of expression of the 'control' probe in our experiments, the gene TEF3 (Swoboda et al., 1994), was consistent with published results (Swoboda et al., 1994). Since neither actin (Paranjape \& Datta, 1991), nor indeed TEF3 or any other Candida gene (Swoboda et al., 1994), could be used as a classic internal loading mRNA control in this experiment, 
CaSRB1 mRNA levels were quantified relative to the major rRNA species (see Methods).

Total RNA isolated from C. albicans growing in either yeast or hyphal form, as well as during the transition between the two forms, showed one distinct band when probed with the CaSRB1 DNA (Fig. 5). This result clearly shows that CaSRB1 is an expressed gene. RNA quantification, however [Fig. 5(b) and (f) for serum and $\mathrm{pH}$ induction, and (d) for the yeast-only growth in rich medium], suggests that the gene might be also regulated. The different induction conditions give slightly different results, although both show a high level of expression early after induction and a considerable reduction after hyphal transition (four- to fivefold, $6 \mathrm{~h}$ after induction). In the experiments where the transcription levels of CaSRB1 were determined after growth in the yeast form in rich medium (Fig. 5c, d), and in minimal medium (data not shown), the pattern of expression was different from that observed under conditions of hyphal induction: there was no reduction in expression levels after $6 \mathrm{~h}$. Taken together, these experiments demonstrate that similar to the situation in S. cerevisiae (Benton et al., 1996), in C. albicans this gene might be also regulated, with levels of expression particularly high during periods of intense cell wall synthesis as in germ tube formation seen during the morphological switch, and bud initiation during growth in the yeast form.

\section{DISCUSSION}

We have cloned and sequenced the functional $C$. albicans homologue of SRB1/PSA1/VIG9. This gene is unique and essential for growth in S. cerevisiae. The data presented here (Fig. 1) suggest that it is most likely unique in the C. albicans genome, although at present it is not known whether the gene is also essential for growth in this species.

Two positive clones were identified out of a fosmid library which, according to our data, appear to define the two copies of this gene in the C. albicans diploid genome. They have almost identical nucleotide and thus amino acid sequences (Fig. 3). The only significant difference is an amino acid polymorphism at position 288 (Gln in clone A, Arg in clone B). Significantly, however, both copies of the Candida gene are able to complement, in S. cerevisiae, the characteristic phenotypes conferred by two different srb1 mutant alleles, including that of the null allele (Fig. 2, Table 2, and lysis data not shown), and have similar patterns of expression under conditions of hyphae induction by $\mathrm{pH}$ and serum (Fig. 5). Given that SRB1/PSA1 is an essential gene for growth in $S$. cerevisiae, the ability of the C. albicans homologues to give functional complementation of its null allele is strong evidence that CaSR B1 indeed encodes GDP-mannose pyrophosphorylase in C. albicans.

The proteins encoded by SRB1/PSA1/VIG9 in $S$. cerevisiae and its functional homologue in C. albicans CaSRB1 appear to be highly conserved. This is shov'n by the high percentages of identity and homology between their amino acid sequences (Fig. 3), as well as their almost identical hydropathy profiles (Fig. 4, and Hashimoto et al., 1997). The protein from C. albicans contains an additional amino acid (glycine, position 254), not present in its $S$. cerevisiae counterpart, although we have no data on its functional or structural significance. We can only speculate that it might be partially responsible for the low survival of the $S$. cerevisiae 7SLU strains transformed with CaSRB1. All the amino acids affected in existing $S R B 1$ mutant alleles (G. Tomlin, S. G. Oliver \& L. I. Stateva, unpublished results) are, however, conserved in the C. albicans homologues, giving indirect proof of their functional importance. Interestingly, there appears to be little conservation of the glycosylation capacity of the proteins. Whilst a computer search identified five potential sites for glycosylation in SRB1/PSA1/VIG9 in $S$. cerevisiae, the same program recognized only one site in CaSRB1. However, our functional complementation data indicate that the glycosylation pattern, if different in vivo, does not affect the function of the protein in a heterologous system.

Outside the sequence of the ORF there is little similarity between the genes from S. cerevisiae and C. albicans. The putative regulatory sites are, however, located in a similar position relative to the first and the final codons of the ORF, and the C. albicans sequences do appear to be sufficient for function in S. cerevisiae, as evidenced by the complementation of different SRB1 mutant phenotypes. Attempts at complementation of a C. albicans CaSRB1 mutant with the $S$. cerevisiae gene will show whether the opposite is also true, although to date heterologous gene expression in Candida has met with little success.

Taken together, all our data suggest strongly that CaSRB1 is the C. albicans gene encoding GDP-mannose pyrophosphorylase and we are currently developing a biochemical analysis to prove this unambiguously.

The gene encoding GDP-mannose pyrophosphorylase in $S$. cerevisiae may be considered as a morphogene, given the plethora of cell-wall-related phenotypes associated with the srb1-1 mutation (G. Tomlin, S. G. Oliver \& L. I. Stateva, unpublished results). There are other microbial mutants with altered morphology which also have defects in genes determining metabolic functions [e.g. glucose-6-phosphate dehydrogenase and phosphoglucomutase in Neurospora crassa (Brody \& Tatum 1966, 1967); NADP-linked glutamate dehydrogenase and phosphoglucose isomerase in $S$. cerevisiae (Wilkinson et al., 1996; Dickinson \& Williams, 1987)]. One conclusion from these data is that many genes make an indirect contribution to morphogenesis acting via a series of pleiotropic effects. In the case of SRB1/ PSA1/VIG9, these pleiotropic effects are determined by the demand for GDP-mannose, either directly or via the dolichol pathway linking a number of basic cellular processes which contribute to the biogenesis of a functional cell envelope $[\mathrm{N}$ - and $\mathrm{O}$-linked glycosylation of proteins (Kukuruzinska et al., 1987; Abeijon \& 
Hirschberg, 1992; Herscovics \& Orlean, 1993); mannosylation of lipids in the Golgi (Lester \& Dickson, 1993) and the synthesis of GPI anchors attached to the C-terminus of some proteins (Orlean, 1990)]. This high demand probably accounts for the high levels of expression of the gene in both $S$. cerevisiae and $C$. albicans (our Northern data ; Benton et al., 1996; Zhang, 1997). In S. cerevisiae, the expression levels of SRB1/ PSA1 vary and are tightly regulated with the cell cycle, with a peak of expression in G1 at START (Benton et al., 1996). Our data indicate that in C. albicans as well, the levels of expression of CaSRB1 are not constant. There are clear changes in mRNA levels following the switch to hyphal growth. Our data also suggest that there might be some periodicity in the rate of mRNA synthesis during growth in the yeast form. It will be interesting to discover how this regulation is achieved. Our future studies on CaSRB1 mutant strains and/or strains expressing the gene under tightly controlled promoters might provide some answers.

\section{ACKNOWLEDGEMENTS}

We thank S. Scherer, G. Tomlin and A. Brown for libraries, plasmids and strains, C. James for help with the sequencing, and N. Gow and A. Brown for productive discussions. This work was supported by a Wellcome grant to R.W. and L.S. and by a scholarship from National Centre for Genetic Engineering and Biotechnology (NCGEB), National Science Technology Development Agency (NSTDA), Ministry of Sciences, Technology and Environment Thailand, and Royal Thai Government to S. W. Patent protection has been sought for this approach under British patent application 9716916.3.

\section{REFERENCES}

Abeijon, C. \& Hirschberg, C. B. (1992). Topography of glycosylation reactions in the endoplasmic reticulum. Trends Biochem $S_{c i}$ $17,32-36$.

Albright, C. F. \& Robbins, P. W. (1990). The sequence and transcript heterogeneity of the yeast gene $A L G 1$, an essential mannosyltransferase involved in $\mathrm{N}$-glycosylation. $\mathrm{J}$ Biol Chem 265, 7042-7049.

Bailey, D. A., Feldman, P. J. F., Bovey, M., Gow, N. A. R. \& Brown, A. J.P. (1996). The Candida albicans HYR1 gene, which is activated in response to hyphal development, belongs to a gene family encoding yeast cell wall proteins. J Bacteriol 178, 5353-5360.

Benton, B. K., Plump, S. D., Roos, J., Lennarz, W. \& Cross, F. R. (1996). Overexpression of Saccharomyces cerevisiae G1 cyclins restores the viability of alg1 $\mathrm{N}$-glycosylation mutants. Curr Genet 29, 106-113.

Birnboim, H. C. \& Doly, J. (1979). A rapid alkaline extraction procedure for screening recombinant plasmid DNA. Nucleic Acids Res 7, 1513-1523.

Blagoeva, J., Stoyev, G. \& Venkov, P. (1991). Glucan structure in a fragile mutant of Saccharomyces cerevisiae. Yeast 7, 455-461.

Brody, S. \& Tatum, E. L. (1966). The primary effect of a morphological mutation in Neurospora crassa. Proc Natl Acad Sci USA 56, 1290-1297.

Brody, S. \& Tatum, E. L. (1967). Phosphoglucomutase mutants and morphological changes in Neurospora crassa. Proc Natl Acad Sci USA 58, 423-430.
Brown, A. J. P. (1994). RNA extraction and mRNA quantitation in Candida albicans. In Molecular Biology of Pathogenic Fungi: a Laboratory Manual, pp. 127-134. Edited by B. Maresca \& G. S. Kobayashi. New York: Telos Press.

Bullock, W. O., Fernandez, J. M. \& Short, J. M. (1987). XL1-Blue - a high-efficiency plasmid transforming recA Escherichia coli strain with $\beta$-galactosidase selection. Biotechniques 5, 376-378.

Casanova, M., Gil, M., Cardenoso, L., Martinez, J.P. \& Sentandreu, R. (1989). Identification of wall specific antigens synthesised during germ tube formation by Candida albicans. Infect Immun 57, 262-271.

Cid, V. J., Duran, A., delRay, F., Snyder, M. P., Nombela, C. \& Sanchez, M. (1995). Molecular basis of cell integrity and morphogenesis in Saccharomyces cerevisiae. Microbiol Rev 59, 345-386.

Debono, M. \& Gordee, R. S (1994). Antibiotics that inhibit fungal cell wall development. Annu Rev Microbiol 48, 471-497

Davis, R., Thomas, M., Cameron, J., John, T. S., Sherer, S. \& Padget, R. (1980). Rapid DNA isolation for enzymatic and hybridisation analysis. Methods Enzymol 65, 404-411.

Dickinson, J. R. \& Williams, A. S. (1987). The $c d c 30$ mutation in Saccharomyces cerevisiae results in a temperature sensitive isoenzyme of phosphoglucose isomerase. J Gen Microbiol 133, $13.5-140$.

Elorza, M. V., Murgai, A. \& Sentandreu, R. (1985). Dimorphism in Candida albicans: contribution of mannoproteins to the architecture of yeast and mycelial cell wall. J Gen Microbiol 131, 2209-2216.

Fonzi, W. A. \& Irwin, M. Y. (1993). Isogenic strain construction and gene mapping in Candida albicans. Genetics 134, 717-728.

Gillum, A. M., Tsay, E. Y. H. \& Kirsch, D. R. (1984). Isolation of the Candida albicans gene for orotidine- 5 '-phosphate decarboxylase by complementation of $S$. cerevisiae ura 3 and E. coli pyrF mutations. Mol Gen Genet 198, 179-182.

Hashimoto, H., Sakakibara, A., Yamasaki, M. \& Yoda, K. (1997). Saccharomyces cerevisiae VIG9 encodes GDP-mannose pyrophosphorylase, which is essential for protein glycosylation. $J$ Biol Chem 272, 16308-16314.

Heale, S. M., Stateva, L. I. \& Oliver, S. G. (1994). Introduction of YACs into intact yeast cells by a procedure which shows low levels of recombinagenicity and co-transformation. Nucleic Acids Res 22, 5011-5015.

Heery, D. M., Cannon, F. \& Powel, R. (1990). A simple method for subcloning DNA fragments from gel slices. Trends Genet 6, 173.

Herrero, E., Valentin, E. \& Sentandreu, R. (1985). Effect of alphafactor on individual wall mannoproteins from Saccharomyces cerevisiae a-cells. FEMS Microbiol Lett 27, 293-297.

Herscovics, A. \& Orlean, P. (1993). Glycoprotein biosynthesis in yeast. $F A S E B J 7,540-550$.

Hill, J., lan, K. A., Donald, G. \& Griffiths, D. E. (1991). DMSOenhanced whole cell yeast transformation. Nucleic Acids Res 19, 5791.

Ito, H., Fukuda, Y., Murata, K. \& Kimara, A. (1983). Transformation of intact yeast cells treated with alkali cations. J Bacteriol 153, 163-168.

James, C. M., Indge, K. J. \& Oliver, S. G. (1995). DNA sequence analysis of a $35 \mathrm{~kb}$ segment from Saccharomyces cerevisiae chromosome VII reveals 19 open reading frames including RAD54, ACE1/CUP2, PMR1, RCK1, AMS1 and CAL1/CDC43. Yeast 11, 1413-1419.

Kim, U., Shizuya, H., deJong, P. J., Birren, B. \& Simon, M. (1992). 
Stable propagation of cosmid sized human DNA inserts in an $\mathrm{F}$ factor based vector. Nucleic Acids Res 20, 1083-1085.

Klis, F. M. (1994). Cell wall assembly in yeast. Yeast 10, 851-869. Kukuruzinska, M. A., Bergh, M. L. E. \& Jackson, B. J. (1987). Protein glycosylation in yeast. Annu Rev Biochem 56, 915-944.

Lee, K. L., Buckley, H. R. \& Campbell, C. C. (1975). An amino acid liquid synthetic medium for the development of mycelial and yeast forms of Candida albicans. Sabouraudia 13, 148-153.

Lehle, L. \& Tanner, W. (1995). Protein glycosylation in yeast. In Glycoproteins, vol. 29a, pp. 475-509. Edited by J. Montreuil, H. Schachter \& J. F. G. Vliegenthart. Amsterdam: Elsevier.

Lester, R. L. \& Dickson, R. C. (1993). Sphingolipids with inositolphosphate-containing head groups. Adv Lipid Res 26, 253-274.

Lipke, P. N., Taylor, A. \& Ballou, C. (1976). Morphogenic effects of alpha-factor on Saccharomyces cerevisiae a cells. J Bacteriol 12, 610-618.

Maerkisch, U., Reuter, G., Stateva, L. I. \& Venkov, P. (1983). Mannan structure analysis of the fragile Saccharomyces cerevisiae mutant VY1160. Int J Biochem 15, 1373-1377.

Mountain, H. A., Bystroem, A. S., Larsen, J. T. \& Korch, C. (1991). Four major transcriptional responses in the methionine/threonine biosynthetic pathway of Saccharomyces cerevisiae. Yeast 7, 781-803.

de Nobel, J. G., Klis, F., Ram, A., Van Unen, H. J., Priem, J., Munnik, T. \& Van den Ende, H. (1991). Cyclic variations in the permeability of the cell wall of Saccharomyces cerevisiae. Yeast 7 , 589-598.

Orlean, P. (1990). Dolichol phosphate mannose synthase is required in vivo for glycosyl phosphatidylinositol membrane anchoring, $\mathrm{O}$-mannosylation, and $\mathrm{N}$-glycosylation of proteins in Saccharomyces cerevisiae. Mol Cell Biol 10, 5796-5805.

Orlean, P., Albright, C. \& Robbins, P. W. (1988). Cloning and sequencing of the yeast gene for dolichol phosphate mannose synthase, an essential protein. J Biol Chem 263, 17499-17507.

Paranjape, V. \& Datta, A. (1991). Overexpression of the actin gene is associated with the morphogenesis of Candida albicans. Biochem Biophys Res Commun 179, 423-427.
Sambrook, J., Fritsch, E. F. \& Maniatis, T. (1989). Molecular Cloning: a Laboratory Manual, 2nd edn. Cold Spring Harbor, NY: Cold Spring Harbor Laboratory.

Sass, P., Field, J., Nikawa, J., Toda, T. \& Wigler, M. (1986). Cloning and characterisation of the high- affinity cAMP phosphodiesterase of Saccharomyces cerevisiae. Proc Natl Acad Sci USA 83, 9303-9307.

Sherman, F., Fink., G. R. \& Hicks, J. B. (1986). Methods in Yeast Genetics. Cold Spring Harbor, NY: Cold Spring Harbor Laboratory.

Sikorski, R. S. \& Hieter, P. (1989). A system of shuttle vectors and yeast host strains designed for efficient manipulation of DNA in Saccharomyces cerevisiae. Genetics 122, 19-27.

Stateva, L. I., Oliver, S. G., Trueman, L. J. \& Venkov, P. V. (1991). Cloning and characterisation of a gene which determines osmotic stability in Saccharomyces cerevisiae. Mol Cell Biol 11, $4235-4243$.

Sundstrom, P., Smith, D. \& Sypherd, P. S. (1990). Sequence analysis and expression of the two genes for elongation factor $1 \alpha$ from the dimorphic yeast Candida albicans. J Bacteriol 172, 2036-2045.

Swoboda, R. K., Bertram, G., Colthrust, D. R., Tuite, M. F., Gow, N. A. R., Gooday, G. W. \& Brown, A. J. (1994). Regulation of the gene encoding translation elongation factor 3 during growth and morphogenesis in Candida albicans. Microbiology 140, 2611-2616.

Venkov, P., Hadjiolov, A., Battaner, E. \& Schlessinger, D. (1974). Saccharomyces cerevisiae sorbitol dependent fragile mutants. Biochem Biophys Res Commun 56, 559-604.

Wilkinson, B. M., James, C. \& Walmsley, R. M. (1996). Partial deletion of the Saccharomyces cerevisiae GDH3 gene results in novel starvation phenotypes. Microbiology 142, 1667-1673.

Yanisch-Perron, C., Vieira, J. \& Messing, J. (1985). Improved M13 phage cloning vectors and host strains: nucleotide sequence of the M13mp18 and pUC19 vectors. Gene 33, 103-119.

Zhang, N. (1997). Genetically-controlled cell lysis in the yeast Saccharomyces cerevisiae. PhD thesis, UMIST, Manchester, UK.

Received 8 January 1998; revised 15 May 1998; accepted 28 May 1998. 